\title{
Fetal Alcohol Spectrum Disorder Diagnosis and Schooling: A Tale of Two Boys and Differing Discourses
}

\author{
Tracey Jongens
}

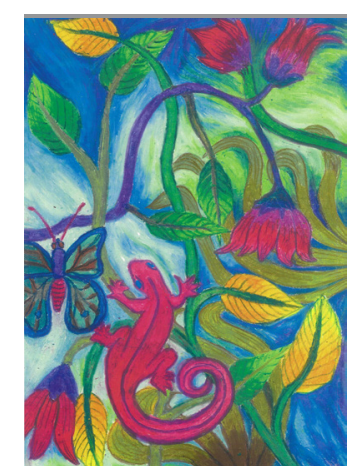

\begin{abstract}
Fetal Alcohol Spectrum Disorder (FASD) is the term to describe the range of adverse effects that can occur when a fetus is exposed to alcohol. At present in New Zealand there are no definitive statistics on the extent of FASD as a prevalence study has not been undertaken. However, as reported in the New Zealand Fetal Alcohol Spectrum Disorder Working Party Report (2016), at least one in two pregnancies are exposed to alcohol, with 10 per cent of these being exposed to high-risk levels. The life-long difficulties that people with FASD experience are becoming clearer as more is learnt about FASD and its effects. This paper describes the recent experience of two Year 11 teens attending different schools in New Zealand. The aim is to highlight the diversity of experience each had, due to the differing approach their school took towards them and their diagnosis of FASD.
\end{abstract}

\section{Storied experience}

Keywords:

fetal alcohol spectrum disorder (FASD)

\section{INTRODUCTION}

The Fetal Alcohol Network of New Zealand describes Fetal Alcohol Spectrum Disorder (FASD) as "a range of significant adverse effects on development when alcohol is consumed during pregnancy. FASD is a brain-based neurodisability that can include physical abnormalities" (Fetal Alcohol Network NZ, n.d., p. 1). The effects of prenatal alcohol exposure include the disruption of brain development and subsequent behavioural, cognitive and motor functions (Riley, Infante \& Warren, 2011). This includes difficulties with attention (Lane et al., 2014), speech/language and spatial memory, planning and organising, and deficits with memory and verbal learning (Green, 2007). Negative life outcomes include a greater likelihood of unemployment, higher hospital admissions for alcohol abuse, and a greater prevalence of psychiatric disorders (compared to those without FASD) (Rangmar et al., 2015).
These difficulties can come to the fore when children with FASD go to school. Here they can struggle with a range of social, academic, behavioural and emotional challenges (Green, 2007). However, while students with FASD cannot be 'cured', there is a range of approaches that can decrease the negative effects of FASD while increasing the likelihood that students with FASD can learn and participate at school. Ensuring that teachers have the knowledge and skills to provide appropriate learning environments for students with FASD is critical (Pei et al., 2015). However, as Carpenter (2011) has argued, "The unusual style of learning and extreme challenging behaviour of (students) affected is out of the experience of many educators and teachers (can) find themselves 'pedagogically bereft' "(p. 42). I believe this to be the experience of most teachers in our New Zealand schools at present. As well as this, teachers' negative beliefs about, and attitudes towards FASD, can impact upon a student's experience in the classroom (Pei et al., 2015).

In the following accounts of personal experience, the effects of teacher-beliefs impacted greatly on the success and outcomes for two students. These effects are long ranging and continue for both of these students way beyond the school gate and over a number of years to the present day.

This is the story of two precious and beloved sons, Jack and Harry. Both live within a two parent, twochild family. Quite by chance both live in rural communities in New Zealand, but in different locations. My knowledge of these stories has come from a personal connection with both of the families involved.

Both names are pseudonyms and permission from both students has been gained to report on their experiences.

\section{JACK}

Jack attended his local rural high school. Jack's parents were drawn to the school as it was a smaller sized school and, they believed, a more nurturing environment for their 'active' son. At the time of enrolling, Jack did have a diagnosis of Attention 
Deficit Hyperactive Disorder (ADHD). On enrolment, they met with the principal and the Special Education Needs Coordinator (SENCO) to ensure the best, most positive start and outcome for their son. Sadly, within one term, he was on suspension and for the following term he was enrolled in an alternative education programme at another site. It was during this time that Jack was diagnosed with FASD. He returned to his high school for Term 4 after a successful time in the alternative education programme, and once again meetings were set up to ensure a positive transition for Jack's return to school and to establish a plan for the following Year 11 year at school, taking into account the new knowledge of FASD.

Jack's parents were very keen to work closely with the school to ensure a positive outcome for their son. Recognising that the teachers may have little understanding of FASD, they proactively provided information and support. They brought in outside specialists to share their knowledge with the teaching team and were eager to see their son happy and experiencing success. Unfortunately, Jack spent his Year 11 attending school for half-days only, a strategy suggested by some of the staff. At one point during the year, it was suggested that Jack might be better off elsewhere. It was often remarked that the fact that Jack had no extra funding 'attached to him' meant the staff were unable to accommodate him. Teachers also seemed to believe that Jack was 'choosing' not to engage, as opposed to experiencing difficulty accessing the learning programme, and this was evident in his final report where a comment was made that Jack "did not see the benefit of goal setting". One teacher, who did try to engage with Jack and provide a more successful environment for him, gave him the one and only certificate that he ever received in school.

The outcome for Jack was he left school at the end of Year 11 with no National Certificate of Educational Achievement (NCEA) credits, he didn't sit any of the external exams and during the internal exams his Special Assessment Conditions ${ }^{1}$ (SAC) were apparently overlooked. He left school disillusioned and believing he was 'dumb'. Four years later, through a lot of family support, Jack is now employed and is beginning to earn NCEA credits through his employer. His Mum sums up his school experience as one of blame and punitive actions, completely lacking in any positive feedback.

\section{HARRY}

Also in Year 11, Harry attended his local area school where he had been since he was six. Harry's

\footnotetext{
1"Special Assessment Conditions (SAC) provide extra help for approved students when they are being assessed for their NCEA so that barriers to achievement can be removed and they then have a fair opportunity to achieve" (Govtnz 2017)
}

diagnosis of FASD was made when he was in Year 8. During Year 9 and 10, Harry participated in the mainstream class programme with some support from a teacher-aide, funded by the school. At the end of his Year 10, Harry was invited to join a new initiative that was to be introduced. Upon recognising a group of students who were not coping academically, a specialist programme was to be set up that would focus on supporting the seven students selected in a highly-supportive literacy class with the aim of ensuring all the students would gain their NCEA literacy credits. The students were encouraged to participate in their 'strength' area mainstream classes, which were the more practical subject options, whilst the academic class load was lessened, enabling the school to provide an intense literacy programme for them. They were mentored, provided with modelling, given extra guided-practice opportunities and reallife experiences, and provided with intense feedback/ feed-forward in preparation for producing their final submissions for each unit standard studied. As a result, each of the students succeeded in attaining their literacy credits as well as their numeracy credits, and their teacher was also able to support them in their other subjects, meaning each of the seven students, who in Year 10 were considered not to be succeeding, achieved their NCEA Level 1. Harry excelled in his strength subject areas and received a prize at the end-of-year prizegiving. On completion of Year 11, Harry spent two more years at school attaining NCEA Level 2 and 3 and went onto a tertiary trades programme with a view to gaining an apprenticeship.

\section{DISCUSSION}

Pei et al. (2015) consider that the views which teachers hold of their students and the quality of their teaching are "significant factors" (p. 135) in educating young people with disabilities. Clark et al. (2014) looked at a variety of studies that led them to state, "In summary, these studies support the hypothesis that changes to the environments of students with FASD may improve behaviour" (p. 26) leading to an improvement in learning outcomes.

Although not the subject of this paper, there is limited diagnostic capacity of FASD in New Zealand at present, however, "diagnosis (is) only as useful as the accommodations and supports that follow" (Pei et al., 2013, p. 331). The information on accommodations and supports is available to New Zealand teachers through the FASD Guide (New Zealand Ministry of Education, 2017). This publication was developed by the New Zealand Ministry of Education as an online guide to provide teachers with information and strategies to support students who have, or are suspected of having, FASD. However, like diagnosis, this information is only going to make a difference when we have teachers and schools willing to try. 
The intent of this paper is to highlight that a student's experience of school, and particularly a student with FASD, can be strongly impacted by their teachers' and the school's approach to supporting them. Whilst it is recognised that students with FASD can present with "unusual learning styles ... and extremely challenging behaviours" (Carpenter, 2011, p. 42), this story supports the view that success can be achieved when teachers and schools are willing to change the environment to meet the needs of their students. In the words of John Hattie, "You can't just teach one way. If kids aren't learning, you're the only one paid to try something different" (Twittercom, 2017).

\section{REFERENCES}

Carpenter, B. (2011). Pedagogically bereft: Improving learning outcomes for children with foetal alcohol spectrum disorders. British Journal of Special Education, 38(1), 37-43.

Clark, E., George, M.A., Hardy, C., Hall, W.A., MacMillan, P.D., Wakabayashi, S., \& Hughes, K. (2014). Exploratory study of the effectiveness of a professional development program on the academic achievement and classroom behavior of students with fetal alcohol spectrum disorder in British Colombia, Canada. International Journal of Alcohol and Drug Research, 3(1), 25-34.

Fetal Alcohol Network New Zealand (n.d.). Fetal alcohol spectrum disorder. Available from http:// www.fan.org.nz/fetal_alcohol_spectrum_disorder

FASD Working Group (2016). Taking action on fetal alcohol spectrum disorder: 2016 -2019: An action plan. Wellington, NZ: Ministry of Health.

Govtnz. (2017). Govtnz. Available at http://www. nzqa.govt.nz/providers-partners/assessment-andmoderation/managing-national-assessment-inschools/special-assessment-conditions/info-forparents-and-caregivers/what-are-sacs/

Green, J. H. (2007). Fetal alcohol spectrum disorders: Understanding the effects of prenatal alcohol exposure and supporting students. Journal of School Health, 77, 103-108. doi:10.1111/j.17461561.2007.00178.x

Lane, K.A., Stewart, J., Femandes, T., Russo, N., Enns, J.T., \& Burack, J.A. (2014). Complexities in understanding attentional functioning among children with fetal alcohol spectrum disorder. Frontiers in Human Neuroscience, 8(119), 27-35.

New Zealand Ministry of Education (2017). Inclusive education. Available at http://www.inclusive.tki. org.nz/guides/fasd/
Pei, J., Job, J., Poth, C., O’Brien-Langer, A., \& Tang, W. (2015). Enhancing learning environments for students affected by fetal alcohol spectrum disorders: An exploratory study of Canadian preservice teacher knowledge and conceptions. Journal of Education and Training Studies, 3(5), 134-143.

Pei, J., Job, J.M., Poth, C., \& Atkinson, E. (2013). Assessment for intervention of children with fetal alcohol spectrum disorders: Perspectives of classroom teachers, administrators, caregivers, and allied professionals. Psychology, 4(3A), 325-334.

Rangmar, J., Huern, A., Vinnerljung, B., Stromland, K., Aronson, M., \& Fahlke, C. (2015). Psychosocial outcomes of fetal alcohol syndrome in adulthood. Pediatrics, 135 (1), 52-58.

Riley, E.P., Infante, M.A., \& Warren, K.R. (2011). Fetal alcohol spectrum disorders: An overview. Neuropsychology Review, 21, 73-80.

Twittercom (2017). Twitter. Available at https://twitter. com/VisibleLearning/status/814322049971695616/ photo/1

\section{AUTHOR PROFILE}

Tracey Jongens

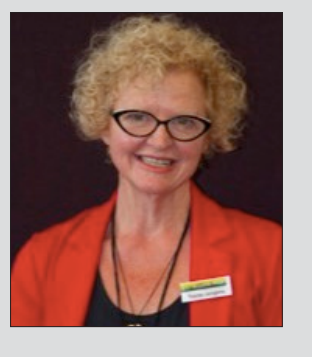

Tracey Jongens is a Resource Teacher of Learning and Behaviour (RTLB) in Te Paeroa Cluster 34 in South and East Christchurch. Prior to this she was a primary school teacher. Tracey has both a professional and personal interest in raising awareness of Fetal Alcohol Spectrum Disorder (FASD) within New Zealand and has recently worked closely with the Ministry of Education and CORE Education in supporting the development of the FASD Guide on the Inclusive TKI website (http://www.inclusive. tki.org.nz/guides/fasd/). Tracey is a founding member of FASD-CAN Inc NZ (http://www.fasd-can.org.nz/)

Email: traceyj@rtlb34.school.nz 